\title{
Incidence and mechanism of neurological deficit after thoracolumbar fractures sustained in motor vehicle collisions
}

\author{
Sourabh Mukherjee, MD, ${ }^{1}$ Chad Beck, MD, ${ }^{1}$ Narayan Yoganandan, PhD, ${ }^{2}$ and Raj D. Rao, MD ${ }^{1}$ \\ Departments of ${ }^{1}$ Orthopaedic Surgery and ${ }^{2}$ Neurosurgery, Medical College of Wisconsin, Milwaukee
}

OBJECTIVE To determine the incidence of and assess the risk factors associated with neurological injury in motor vehicle occupants who sustain fractures of the thoracolumbar spine.

METHODS In this study, the authors queried medical, vehicle, and crash data elements from the Crash Injury Research and Engineering Network (CIREN), a prospectively gathered multicenter database compiled from Level I trauma centers. Subjects had fractures involving the T1-L5 vertebral segments, an Abbreviated Injury Scale (AIS) score of $\geq 3$, or injury to 2 body regions with an AIS score of $\geq 2$ in each region. Demographic parameters obtained for all subjects included age, sex, height, body weight, and body mass index. Clinical parameters obtained included the level of the injured vertebra and the level and type of spinal cord injury. Vehicular crash data included vehicle make, seatbelt type, and usage and appropriate use of the seatbelt. Crash data parameters included the principal direction of force, change in velocity on impact $(\Delta \mathrm{V})$, airbag deployment, and vehicle rollover. The authors performed a univariate analysis of the incidence and the odds of sustaining spinal neurological injury associated with major thoracolumbar fractures with respect to the demographic, clinical, and crash parameters.

RESULTS Neurological deficit associated with thoracolumbar fracture was most frequent at extremes of age; the highest rates were in the 0 - to 10 -year (26.7\% [4 of 15]) and 70- to 80 -year (18.4\% [7 of 38]) age groups. Underweight occupants (OR 3.52 [Cl 1.055-11.7]) and obese occupants (OR 3.27 [Cl 1.28-8.31]) both had higher odds of sustaining spinal cord injury than occupants with a normal body mass index. The highest risk of neurological injury existed in crashes in which airbags deployed and the occupant was not restrained by a seatbelt (OR 2.35 [Cl $0.087-1.62]$ ). Reduction in the risk of neurological injuries occurred when 3-point seatbelts were used correctly in conjunction with the deployment of airbags (OR 0.34 [Cl 1.3-6.6]) compared with the occupants who were not restrained by a seatbelt and for whom airbags were not deployed. Crashes with a $\Delta \mathrm{V}$ greater than $50 \mathrm{~km} /$ hour had a significantly higher risk of spinal cord injury (OR $3.45[\mathrm{Cl} 0.136-0.617])$ than those at lower $\Delta \mathrm{V}$ values.

CONCLUSIONS Deployment of airbags was protective against neurological injury only when used in conjunction with 3-point seatbelts. Vehicle occupants who were either obese or underweight, very young or elderly, and those in crashes with a $\Delta V$ greater than $50 \mathrm{~km} /$ hour were at higher risk of thoracolumbar neurological injury. Neurological injury at thoracic and lumbar levels was associated with multiple factors, including the incidence of fatality, occupant factors such as age and body habitus, energy at impact, and direction of impact. Current vehicle safety technologies are geared toward a normative body morphology and need to be reevaluated for various body morphologies and torso compliances to lower the risk of neurological injury resulting from thoracolumbar fractures.

http://thejns.org/doi/abs/10.3171/2015.4.SPINE15194

KEY WORDS motor vehicle collision; neurological injury; CIREN; trauma

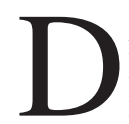

ATA recently published by the National Spinal Cord Injury Statistical Center show that the most common cause of spinal cord injury (SCI) in the United States between 2010 and 2013 was motor vehicle collisions (MVCs) (37.9\%), followed by falls (29.9\%). ${ }^{27}$ The incidence of SCI from MVCs alone decreased significantly compared with data obtained from 2000 to 2004 (47.4\%), which suggests that improvements in motor vehicle safety design features, and possibly increased use of these safety features, are being effective. ${ }^{27}$ The societal costs and indi-

ABBREVIATIONS AIS = Abbreviated Injury Scale; ASIA = American Spinal Injury Association; BMI = body mass index; $\mathrm{CIREN}=$ Crash Injury Research and Engineering Network; ISS = injury severity score; MVC = motor vehicle collision; NHTSA = National Highway Traffic Safety Administration; PDOF = principal direction of force; $\mathrm{SCl}$ = spinal cord injury.

SUBMITTED February 16, 2015. ACCEPTED April 22, 2015.

INCLUDE WHEN CITING Published online October 9, 2015; DOI: 10.3171/2015.4.SPINE15194. 
vidual disability of neurological deficits that result from MVCs are substantial. It is estimated that the average direct costs of health care and living expenses for an individual with SCI are $\$ 70,849$ per year in 2013 US dollars. ${ }^{27}$

Several authors previously investigated factors that predispose to SCI after an MVC. $3,28,40,44,47$ These previous studies were generally based on subsets of data from a single institution or state and frequently included injuries sustained not just by vehicle occupants but also by pedestrians and motorcycle riders involved in the collision, who are subject to different mechanisms of injury. ${ }^{3,29,44}$ Some authors reported an increased risk of SCI after rollover collisions compared with that after collisions without vehicle rollover, after single-vehicle collisions compared with that after multiple-vehicle collisions, and in occupants of sports utility vehicles compared with those in sedans. ${ }^{3,29,30,44,47}$

The purpose of our study was to determine the incidence of and assess the risk factors associated with thoracic- and lumbar-level neurological injury in vehicle occupants who sustain fractures of the thoracolumbar spine after an MVC. We specifically compared risk factors associated with neurologically complete SCI (American Spinal Injury Association [ASIA] Grade A) in vehicle occupants with those with incomplete SCI (ASIA Grade $\mathrm{B}, \mathrm{C}$, or D) ${ }^{21}$ We performed our investigation using data from the Crash Injury Research and Engineering Network (CIREN), a multicenter national database of MVCs maintained by the National Highway Traffic Safety Administration (NHTSA). The study was based on data collected over a 16-year period between 1996 and 2011 and was limited to motor vehicle occupants with moderate or severe injuries that required admission to a Level I trauma center. To our knowledge, there have been no previous studies that specifically addressed this pattern of thoracolumbar neurological injury resulting from fractures sustained in an MVC.

\section{Methods}

We analyzed data from the CIREN database. CIREN is a prospectively collected database of MVCs maintained by 12 Level I trauma centers in the United States and contains medical, vehicle, and collision data elements gathered by a multidisciplinary team consisting of trauma surgeons, emergency physicians, medical examiners, trauma nurses, epidemiologists, collision investigators, engineers, sociologists, and computer data analysts. Each subject was transported within 24 hours of the MVC to a Level I trauma center registered with the CIREN program. ${ }^{42}$ Minor vehicle collisions were excluded by including only vehicle occupants who sustained injury to 1 body region with an Abbreviated Injury Scale (AIS) (Table 1) score of $\geq 3$ or who injured 2 body regions with an AIS score of $\geq 2$ in each region. An injury severity score (ISS) was calculated for each subject in the database by squaring his or her 3 highest AIS system scores and adding the 3 numbers. ${ }^{18}$ Collisions that involve vehicles that are more than 6 years old and data regarding pedestrians or bicycle or motorcycle riders involved in the collision are excluded from the database.
TABLE 1. Summary of AIS scores and descriptions

\begin{tabular}{lc}
\hline \multicolumn{1}{c}{ Injury Severity* } & AIS Score \\
\hline Minor & 1 \\
\hline Moderate & 2 \\
\hline Severe but not life threatening & 3 \\
\hline Serious, life threatening, but survival probable & 4 \\
\hline Critical, survival uncertain & 5 \\
\hline Virtually unsurvivable & 6 \\
\hline
\end{tabular}

* Rated separately in 6 discrete body regions (head, face, chest, abdomen, extremities [including pelvis], external).

We queried and analyzed the CIREN database for all vehicle occupants who sustained fractures involving the T1-L5 vertebral segments. Demographic parameters obtained on the occupants included age, sex, stature, body weight, and body mass index (BMI). Clinical parameters obtained on all study occupants included the level of the injured vertebra, the level and type of SCI, and the presence of associated injuries of the pelvis, thoracic cage, or cervical spine. ${ }^{8}$ Radiographic images, computed tomography with sagittal and coronal reconstructions, and MR images (when available) on the thoracic and lumbar spine for each occupant were reviewed independently by 2 spine surgeons. ${ }^{32}$ We classified occupant thoracolumbar fractures according to a modification of the original Denis classification. A number of occupants in the MVCs sustained injury characterized by distractive failure of the anterior column through the disc, or vertebral body and disc, with or without additional distraction of the middle column or translation at the fracture site. Distractive extension injuries were defined as a distinct "major injury" group that are not accounted for in the original Denis classification..$^{32}$ The vertebral level of injury was recorded; major injuries were categorized as being in 1 of 3 distinct regions: thoracic (T-1 to T10-11), thoracolumbar junction (T11-L2), and lumbar (L2-3 to L5-S1). The ASIA Impairment Scale was used to differentiate complete and incomplete SCIs. ASIA Grade A injury with no sensory or motor function in sacral segments S4-5 was classified as a complete SCI. ${ }^{22}$ ASIA Grade B, C, and D injuries resulting in impaired spinal cord function but sparing partial or complete sacral segments (S4-5 sensory or motor function) were classified as incomplete SCIs. ${ }^{15,22}$ Injury to the lumbosacral nerve roots is not classified by the ASIA Impairment Scale and are reported separately in this article. ${ }^{15}$

Collision data included vehicle make, model, and year of manufacture, seat type and orientation, and seatbelt type (3-point or 2-point lap belt). Seatbelt usage was determined based on witness marks on the belt webbing and points of friction or stretch of the belt; photographs showing belt-induced bruises or injury; and police reports corroborated by reports of the emergency medical services crew. Seatbelt usage was defined as being in 1 of 4 categories, namely, 1) appropriate use of a 3-point belt, 2) use of a 2-point belt, 3) use of a 3-point belt with the shoulder belt worn under the arm or behind the shoulders, and 4) absence any seat restraint use. The location of each case occupant was recorded in terms of whether the oc- 
cupant was on the passenger or driver side and the specific seat row. A "collision-reconstruction team" examined the scene of the MVC and the motor vehicle involved in the collision to document the collision characteristics. Photographs and diagrams of each collision site were recorded to document the direction and nature of the MVC. Collision data parameters were analyzed to understand the kinematics of the vehicle and occupants and included the principal direction of force (PDOF), the change in velocity on impact $(\Delta \mathrm{V})$, the deployment of safety restraints such as airbags, the type and usage of seatbelts, and vehicle rollovers. The PDOF is the angle between the vehicle's longitudinal axis and the resultant forces acting on the vehicle at impact. ${ }^{34,45}$ It is measured clockwise positive and ranges from $0^{\circ}$ to $359^{\circ} .{ }^{45}$ Motor vehicle collisions with a PDOF between $315^{\circ}$ and $360^{\circ}$ or between $0^{\circ}$ and $45^{\circ}$ were considered frontal MVCs. ${ }^{34}$ Collisions with a PDOF between $226^{\circ}$ and $315^{\circ}$ on the left side or $46^{\circ}$ and $135^{\circ}$ on the right side were considered lateral collisions. ${ }^{34} \Delta \mathrm{V}$ is defined as the total change in velocity of the motor vehicle over the duration of the collision event. ${ }^{7}$ The collision $\Delta \mathrm{V}$ differs from the preimpact velocity of the vehicle because the vehicle continues to move after the collision. In collisions that involve 2 motor vehicles, the $\Delta \mathrm{V}$ is calculated as the difference in the impact velocity and the separation velocity. The WinSMASH software program, available through the NHTSA, was used to calculate the $\Delta \mathrm{V}$ from the vehicle's weight, the vehicle's mass, the crush profile, and the PDOF. ${ }^{26,34}$ Case occupants were categorized into 1 of 2 groups, $\Delta \mathrm{V}<50 \mathrm{~km} /$ hour or $>50 \mathrm{~km} /$ hour, for brevity of analysis in accordance with federal motor vehicle Standard 208 value of $48.2 \mathrm{~km} /$ hour (30 miles/hour). Spinal cord injury in fatalities was determined from autopsy records or, when available, medical records in the emergency department and admission to the trauma center.

\section{Statistical Analysis}

Using a univariate analysis, the incidence and relative risk of spinal neurological injury associated with major thoracolumbar fractures with respect to the demographic, clinical, and collision parameters were recorded and compared with those of the case occupants with major thoracolumbar fractures without spinal neurological injury. The data were analyzed for statistical significance using odds ratios and $95 \%$ confidence intervals.

\section{Review Board Approval}

Clinical data on the vehicle occupants were gathered from the institutional medical records, radiographs, preoperative and intraoperative photographs, autopsies, and police and emergency medical services reports, after obtaining consent of the admitted patients or their next of kin. Institutional review board approval was obtained before the study.

\section{Results \\ Study Cohort Characteristics}

A total of 4595 case occupants were registered in the CIREN database; 631 of these case occupants had thoracolumbar vertebral fractures, 299 of which were ma- jor vertebral fractures and 332 were minor vertebral fractures. None of the 332 subjects with minor vertebral fractures sustained a thoracolumbar spinal cord or lumbosacral nerve root injury. Of the 299 subjects with major thoracolumbar vertebral fractures, 45 (15.05\%) had an associated neurological deficit. Spinal cord injury occurred in $36(80 \%)$ of 45 subjects with a neurological deficit, 4 $(8.9 \%)$ subjects sustained an injury to the conus medullaris, and $5(11.11 \%)$ subjects sustained an injury to the lumbosacral nerve roots. Seven $(2.34 \%)$ of 299 subjects with major thoracolumbar fractures and $2(0.6 \%)$ of 332 subjects with minor thoracolumbar fractures had concurrent cervical cord injuries. None of these subjects with a cervical cord injury sustained neurological injury from the thoracic or lumbar region and were therefore excluded from the analyses.

\section{Occupant Demographic Factors \\ Age Distribution}

Spinal cord injury in a thoracolumbar fracture was observed most frequently at extremes of age; $26.7 \%$ (4 of 15) of the occupants were in the 0 - to 10 -year age group, and $18.4 \%$ ( 7 of 38 ) of occupants were in the 70- to 80-year age group. In comparison, only $7.7 \%$ (2 of 26) of occupants in the 30- to 40-year age group and 7.7\% (3 of 39) in the 40- to 50-year age group sustained an SCI associated with a thoracolumbar fracture.

Spinal cord injury was complete (ASIA Grade A) in $50 \%$ (18 of 36) of all occupants with SCI. A higher risk of sustaining a complete SCI was seen in children between 0 and 10 years of age (20\% [3 of 15]) and in elderly subjects between 70 and 80 years of age (7.9\% [3 of 38]) than in young adults between 30 and 40 years of age (3.8\% [1 of 26]). Although the numbers are small, $60 \%$ (3 of 5) of the subjects who sustained a lumbosacral nerve root injury were from the youngest age groups (10-20 years, 40\% [2 of 5]; 0-10 years, 20\% [1 of 5]) (Fig. 1). The numbers of occupants with conus medullaris injuries were evenly spread among the age groups.

\section{Sex Distribution}

The odds of sustaining a neurological deficit associated with a thoracolumbar vertebral fracture were similar for male and female occupants (OR 1.142 [CI 0.6-2.1]). Although SCI was more frequently found to be neurologically complete (ASIA Grade A) in male (13 of 151 [8.6\%]) subjects than in female (5 of 148 [3.4\%]) subjects, the odds of sustaining an ASIA Grade A SCI were not significantly different among the sexes (OR 2.75 [CI 0.95-7.9]). All 5 subjects with conus medullaris injury and a majority (4 of $5[80 \%])$ of the subjects with lumbosacral nerve root injury, however, were female subjects (Table 2).

\section{Body Mass Index}

Both underweight $\left(\mathrm{BMI}<18.5 \mathrm{~kg} / \mathrm{m}^{2}\right)$ and obese (BMI $>30 \mathrm{~kg} / \mathrm{m}^{2}$ ) occupants with thoracolumbar fractures were at higher risk for neurological injury after an MVC (ORs 3.52 [CI 1.055-11.7] and 3.27 [CI 1.28-8.31], respectively) than occupants with a normal BMI $\left(18.5-25 \mathrm{~kg} / \mathrm{m}^{2}\right)$. Forty percent ( 2 of 5 ) of the lumbosacral nerve root injuries 


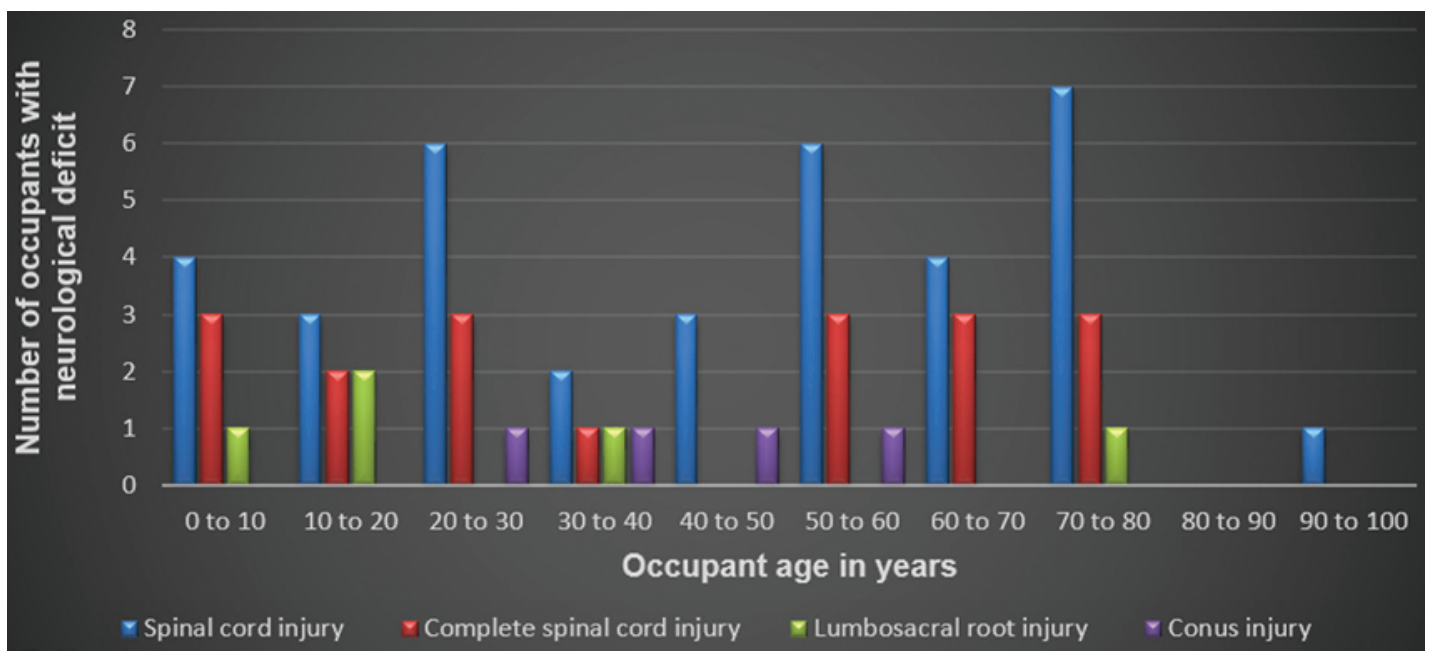

FIG. 1. Incidence of neurological deficits, distributed according to age, in subjects with thoracolumbar fractures sustained in an MVC. Figure is available in color online only.

were sustained by underweight subjects (BMI $<18.5 \mathrm{~kg}$ / $\mathrm{m}^{2}$ ). Although no obese subject sustained a lumbosacral nerve root injury, an increased risk of conus medullaris injury was associated with a higher BMI; $50 \%$ (2 of 4) and $25 \%$ (1 of 4) of the conus injuries were seen in overweight and obese subjects, respectively.

\section{Collision Reconstruction}

\section{Principal Direction of Force}

Frontal collisions were associated with $77.6 \%$ (232 of 299) of major thoracolumbar fractures and $73.3 \%$ (33 of 45) of occupants with SCI. The odds of sustaining a thoracolumbar neurological injury in frontal- and lateralimpact collisions were similar (OR 0.86 [CI 0.39-1.86]) (Table 2). Lumbosacral nerve root and conus medullaris injury were strongly associated with frontal collisions; all 5 occupants with lumbosacral nerve root injury and 4 occupants with conus medullaris injury occurred with frontal collisions.

\section{Vehicle Rollover}

Rollover collisions accounted for $25.1 \%$ (75 of 299) of the MVCs in this series. Occupants of vehicles in rollover collisions who sustained thoracolumbar fractures had lower odds of thoracolumbar SCI than those in nonrollover collisions, but the difference was not significant (OR 0.71 [CI 0.73-13.66]) (Table 3). Although the small numbers preclude statistical significance, $80 \%$ (4 of 5) of the lumbosacral nerve root injuries were associated with non-rollover collisions. Vehicle rollover did not seem to influence the probability of conus medullaris injury, with a similar risk of injury in both groups.

\section{Change in Velocity on Impact}

Subjects who sustained thoracolumbar fractures in collisions with a $\Delta \mathrm{V}$ greater than $50 \mathrm{~km} /$ hour had higher odds of neurological injury (OR 3.45 [CI 0.136-0.617]) than those who sustained thoracolumbar fractures at a lower $\Delta \mathrm{V}$ value (Table 2). Higher $\Delta \mathrm{V}$ values were also associated

TABLE 2. Odds of sustaining neurological deficit under various conditions

\begin{tabular}{lllc}
\hline \multicolumn{1}{c}{ Condition 1 } & \multicolumn{1}{c}{ Condition 2 } & OR & Cl \\
\hline Male & Female & 1.14 & $0.6-2.1$ \\
\hline Underweight (BMI <18.5) & Normal weight (BMI 18.5-25) & 3.5 & $1.05-11.7$ \\
\hline Overweight (BMI 25-30) & Normal weight (BMI 18.5-25) & 2.8 & $0.19-1.8$ \\
\hline Obese $(\mathrm{BMI}>30)$ & Normal weight (BMl 18.5-25) & 3.27 & $1.3-8.3$ \\
\hline$\Delta$ V >50 & $\Delta \mathrm{V}<50$ & 3.45 & $0.14-0.6$ \\
\hline Frontal impact & Lateral impact & 0.86 & $0.4-1.9$ \\
\hline Rollover collision & Non-rollover collision & 0.7 & $0.32-1.55$ \\
\hline Airbag alone & Airbag + 3-point seatbelt & 4.27 & $1.7-10.8$ \\
\hline 3-point seatbelt & Airbag + 3-point seatbelt & 3.3 & $1.11-9.7$ \\
\hline Unrestrained & Airbag + 3-point seatbelt & 2.9 & $1.3-6.6$ \\
\hline Airbags & Unrestrained & 1.44 & $0.44-4.7$ \\
\hline 3-point seatbelt & Unrestrained & 0.83 & $0.23-3.07$ \\
\hline Incorrectly used seatbelt & Unrestrained & 1.15 & $0.23-5.65$ \\
\hline
\end{tabular}


TABLE 3. Odds of sustaining $\mathrm{SCl}$ under various conditions

\begin{tabular}{lllc}
\hline \multicolumn{1}{c}{ Condition 1 } & \multicolumn{1}{c}{ Condition 2 } & $\mathrm{OR}$ & $\mathrm{Cl}$ \\
\hline Male & Female & 1.8 & $0.9-3.8$ \\
\hline Underweight $(\mathrm{BMI}<18.5)$ & Normal weight (BMI 18.5-25) & 2.4 & $0.6-10.4$ \\
\hline Overweight (BMI 25-30) & Normal weight (BMI 18.5-25) & 2.5 & $0.98-6.4$ \\
\hline Obese $(\mathrm{BMI}>30)$ & Normal weight (BMI 18.5-25) & 3.8 & $0.7-7.5$ \\
\hline$\Delta \mathrm{V}>50$ & $\Delta \mathrm{V}<50$ & 2.39 & $0.19-0.9$ \\
\hline Frontal impact & Lateral impact & 0.6 & $0.27-1.3$ \\
\hline Rollover collision & Non-rollover collision & 0.79 & $0.3-1.8$ \\
\hline Airbag alone & Airbag + 3-point seatbelt & 5.5 & $1.9-15.4$ \\
\hline 3-point seatbelt & Airbag + 3-point seatbelt & 2.3 & $1.6-8.2$ \\
\hline Unrestrained & Airbag + 3-point seatbelt & 4.3 & $1.2-14.7$ \\
\hline Airbags & Unrestrained & 1.3 & $0.4-4.2$ \\
\hline 3-point seatbelt & Unrestrained & 0.52 & $0.05-2.1$ \\
\hline Incorrectly used seatbelt & Unrestrained & 0.7 & $0.12-4.1$ \\
\hline
\end{tabular}

with a higher risk of SCI (OR 0.418 [CI 0.18-0.92]) (Table $3)$. The $\Delta \mathrm{V}$ values associated with 2 of 4 subjects with conus medullaris injury and 3 of 5 subjects with lumbosacral injury were unknown, and the remaining cases of conus medullaris and lumbosacral root injury resulted from collisions associated with a $\Delta \mathrm{V}$ greater than $50 \mathrm{~km} /$ hour.

\section{Vehicular Safety Restraints}

Collisions in which airbags deployed and the occupant was not restrained by a seatbelt had the highest risk of sustaining thoracolumbar neurological injury compared with all other case occupants in the study (OR 2.34 [CI $0.087-1.62]$ ), although this result was not statistically significant. Occupants of collisions restrained by a seatbelt in conjunction with airbag deployment had substantially reduced odds of sustaining a thoracolumbar neurological deficit in comparison with unrestrained occupants in an MVC in which airbags were absent or did not deploy (OR 0.34 [CI 1.3-6.6]). Airbag deployment in conjunction with seatbelt use was also more effective in decreasing the odds of neurological deficit than was seatbelt use without concurrent airbag deployment (OR 0.3 [CI 1.12-9.70]) (Table 2).

Airbag deployment reduced the risk of sustaining severe (ASIA Grade A) spinal cord injuries in unrestrained occupants compared with when airbags did not deploy in unrestrained occupants (OR 0.80 [CI 3.8-6.05]). On the other hand, correct 3-point seatbelt use and concurrent deployment of airbags did not provide similar protection against lumbosacral nerve root injury. Two occupants sustained lumbosacral nerve root injury despite correctly applied 3-point seatbelts in conjunction with airbag deployment, whereas none occurred in vehicle occupants restrained by a correctly applied 3-point seatbelt without airbag deployment, those without seatbelt restraint and airbag deployment, and those without any vehicular safety restraint. One of 4 occupants who developed a major thoracolumbar fracture and was restrained by a lap belt alone sustained an SCI. Incorrectly applied 3-point seatbelts that effectively functioned as 2-point restraints were as- sociated with higher odds of sustaining complete (ASIA Grade A) SCI (OR 1.282 [CI 5.2703-8.6610]) (Table 3). Occupants restrained by a 3-point seatbelt with concurrent airbag deployment sustained a low frequency of conus medullaris injury ( 1 of 146 [0.68\%]), whereas a relatively higher frequency was seen both in occupants restrained by a 3-point seatbelt when airbags did not deploy ( 2 of 39 [5.1\%]) and in those who were not restrained by a 3-point seatbelt when airbags were deployed (1 of 46 [2.17\%]).

\section{Severity of Injury}

Injury Severity Score

Major thoracolumbar fractures occurred more frequently in subjects with low ISSs ranging from 10 to 20 (38.46\% [115 of 299]) than those with midrange ISSs ranging from 20 to 30 (28.76\% [86 of 299]), and only $11 \%$ (33 of 299) of the major thoracolumbar fractures reported were in subjects with an ISS of $>70$. The risk of SCI, on the other hand, was higher with overall injury severity, with 56.3\% (9 of 16) of SCIs occurring with higher ISSs ranging from 71 to 80 . At higher ISSs, SCI was also frequently found to be neurologically complete (ASIA Grade A), and the highest incidence was associated with ISSs ranging from 71 to 80 (7 of 16 [43.75\%]). The incidence of lumbosacral nerve root injury and conus medullaris also showed a positive correlation with higher ISSs, with subjects with an ISS ranging from 51 to 60 accounting for $20 \%$ (1 of 5) of subjects with lumbosacral root injury and $25 \%$ (1 of 4) of subjects with conus medullaris injury, although the small numbers preclude statistical significance.

\section{Fatality}

Of 45 collisions associated with major thoracolumbar fractures with neurological deficit in the occupants, $25(56 \%)$ were fatal compared with $22(8.7 \%)$ of the 254 without neurological deficit. The presence of neurological deficit associated with thoracolumbar fractures was associated with substantially higher odds of fatality in MVC occupants (OR 13.1 [CI 6.3-27.13]). The odds of fatality were even higher in subjects with complete (ASIA Grade 
A) SCI (OR 18.8 [CI 6.3-55.9]) than in subjects with no neurological deficit (Table 4). No fatalities occurred in occupants who sustained lumbosacral nerve root injuries associated with a thoracolumbar fracture.

\section{Discussion}

The present investigation specifically addressed neurological injury from fractures of the thoracolumbar spine in vehicle occupants involved in an MVC. A high incidence of neurological injury was observed in elderly occupants who sustained thoracolumbar fracture. Several factors unique to the pathogenesis of traumatic SCI in elderly occupants may account for the increased risk of neurological injury after spine trauma. A decreased injury tolerance of the thoracic cage in the elderly is well documented in the literature $\mathrm{e}^{14,20,35,49}$ and has been attributed to a decrease in the elastic modulus of bone, decreased cross section of the cortex of the ribs, and a more perpendicular rib angle with respect to the vertebra..$^{13} \mathrm{~A}$ higher incidence of preexisting asymptomatic thoracic spinal canal stenosis in elderly subjects has also been reported, which may predispose them to neurological deficits after injury to this region..$^{13}$ Lower energy is required to produce a fracture in an elderly osteoporotic vertebra, possibly resulting in a greater likelihood of bony retropulsion and neurological injury. ${ }^{4}$ Finally, central nervous tissue in the elderly has a unique response to mechanical injury that may differ from that of younger people. ${ }^{48} \mathrm{~A}$ mechanical insult to CNS tissue in the elderly leads to an acceleration of the neurodegenerative process of protein aggregation in the neurons, which causes irreversible neurological damage. ${ }^{1,16,17,48}$ We hypothesize that because of the changes in compliance of the thoracic cage, the thoracic spine and neural tissues are protected less in older vehicle occupants than in younger occupants. To the best of our knowledge, the increased likelihood of thoracolumbar neurological injury in the elderly after an MVC has not been reported previously.

Several previous studies addressed a sex-dependent risk of injury resulting from an MVC. One study reported that female seatbelt-restrained occupants were at a significant- ly higher risk of moderate (AIS score $\geq 2$ ) spine, chest, and head injury from an MVC than male restrained occupants under similar collision conditions, although this increased incidence may be offset in the general population by a lower likelihood of seatbelt use in males, more speeding by male drivers, and more high-velocity collisions in male drivers. ${ }^{2,11,19} \mathrm{~A}$ higher incidence of SCI in males was previously attributed to sex-related behavior patterns, including a greater incidence of speeding and drunk driving in young male drivers that increases the risk of high-velocity MVCs. ${ }^{9,30,31,44}$ In this study, we found an increased prevalence of more severe (ASIA Grade A) SCI in males but, contrary to previous studies, did not find occupant sex to be an important determinant of overall thoracolumbar neurological deficit. In subjects with neurological injury associated with major thoracolumbar fractures, the $\Delta \mathrm{V}$, or preimpact velocity, was higher in male occupants (49.6) than in female occupants (43.9), which supports previously found changes in sex-related driving habits that may have contributed to the higher incidence of high-grade neurological injury in male occupants. Overall injury severity, demonstrated by ISSs, was also higher in males (25.84) than in females (20.97) in our study cohort, again possibly because of higher energy at impact. A factor that may account for the lack of difference in odds of overall neurological injury in males and females may be the higher incidence of fatality in males and our inability to evaluate neurological function in this subset.

The "sudden stop" or magnitude of $\Delta \mathrm{V}$ of the motor vehicle at impact results in increased transmission of energy to occupant tissues and greater severity of occupant injury. ${ }^{34}$ Higher $\Delta \mathrm{V}$ values have also been associated with a greater deformation of the passenger compartment, which leads to increased risk of spinal injury. ${ }^{37}$ Our study found a higher risk of both SCI and overall injury severity (as assessed by ISS) associated with a $\Delta \mathrm{V}$ of $>50 \mathrm{~km} /$ hour. In 2005, Smith et al. ${ }^{40}$ reported that $75 \%$ (6 of 8) of occupants who sustained thoracic SCI were involved in an MVC with a $\Delta \mathrm{V}$ of less than $47.4 \mathrm{~km} /$ hour, despite an equal distribution of occupants with thoracic spine fractures above and below this $\Delta \mathrm{V}$ level. The preponderance

TABLE 4. Odds of sustaining complete (ASIA Grade A) SCI under various conditions

\begin{tabular}{llcc}
\hline \multicolumn{1}{c}{ Condition 1 } & \multicolumn{1}{c}{ Condition 2 } & OR & Cl \\
\hline Male & Female & 2.7 & 0.95 \\
\hline Underweight (BMI <18.5) & Normal weight (BMI 18.5-25) & - & - \\
\hline Overweight(BMI 25-30) & Normal weight (BMI 18.5-25) & 3.2 & $0.74-13.7$ \\
\hline Obese (BMI >30) & Normal weight (BMI 18.5-25) & 1.429 & $0.42-4.8$ \\
\hline$\Delta$ V >50 & $\Delta$ V <50 & 1.47 & $0.18-1.99$ \\
\hline Frontal impact & Lateral impact & 0.79 & $0.24-2.5$ \\
\hline Rollover collision & Non-rollover collision & 1.15 & $0.4-3.3$ \\
\hline Airbag alone & Airbag + 3-point seatbelt & 3.4 & $0.8-4.09$ \\
\hline 3-point seatbelt & Airbag + 3-point seatbelt & 0.9 & -2.3 to 2.15 \\
\hline Unrestrained & Airbag + 3-point seatbelt & 4.3 & $0.9-20.9$ \\
\hline Airbags & Unrestrained & 0.8 & $3.8-6.05$ \\
\hline 3-point seatbelt & Unrestrained & 0.2 & $0.015-3.2$ \\
\hline Incorrectly used seatbelt & Unrestrained & 1.3 & $5.2-8.6$ \\
\hline
\end{tabular}


of SCIs associated with thoracic fractures at lower $\Delta \mathrm{V}$ values in the study by Smith et al. may be attributable to the significantly higher fatality rate seen in occupants with spine fractures sustained at a $\Delta \mathrm{V}$ of $>47.4 \mathrm{~km} /$ hour in both frontal (64.39\%) and lateral (57.9\%) MVCs and the challenge of documenting neurological injury in this group. Federal motor vehicle safety standards require motor vehicles to be able to sustain a frontal collision with a $\Delta \mathrm{V}$ of 30 miles/hour (48.2 km/hour). ${ }^{5}$ We suggest that MVC testing at higher values of $\Delta \mathrm{V}$ may be required to assess the effectiveness of occupant safety restraints, especially with respect to preventing thoracolumbar spinal cord and lumbosacral nerve root injuries. We believe that the higher risk of neurological injury with a $\Delta \mathrm{V}$ of $>50 \mathrm{~km} /$ hour may represent a significant public health problem; in the present study, one-third (29.6\%) of the collisions in which the $\Delta \mathrm{V}$ was known occurred above the current federal motor vehicle safety standard.

The appropriate use of 3-point seatbelts has been shown to substantially reduce the risk of occupant fatality (43\%) and offers protection against face, chest, and pelvic injuries. ${ }^{6,12} \mathrm{We}$ found that appropriately used 3-point seatbelts marginally decreased the risk of neurological injury from thoracolumbar fractures even in the absence of concurrent deployment of airbags. However, the protective effect of seatbelt use was clearly evident in conjunction with the deployment of airbags. From a study on 214 subjects from the CIREN database who sustained spine and spinal cord injuries, Smith et al. reported similar findings, including a decreased risk of spinal cord injuries when 3-point seatbelts were used and airbags concurrently deployed. ${ }^{40}$ In fact, present data indicate that when airbags deploy and seatbelts are not used, there is an increased risk of neurological injury. Our finding is consistent with those in previous reports of airbags being an effective safety restraint only in conjunction with appropriately used 3-point seatbelts. . $^{33,46}$ Reed et al. ${ }^{33}$ reported a significant decrease in AIS Score 3 thoracolumbar spinal column injury with seatbelt use in conjunction with airbag deployment but did not find any protective effect associated with airbag deployment alone. In another retrospective study based on the Crash Outcome Data Evaluation System (CODES) database, Wang et $a l .{ }^{46}$ found a significantly higher risk of thoracic spine fractures with airbag deployment alone and a protective effect from seatbelts only when they were used along with airbag deployment. The authors of previous investigations have reported other injuries caused by airbag inflation, including rib fractures and abdominal, facial, and cervical spine injuries..$^{10,25,39,43}$ Our findings of an increased risk of overall spinal neurological injury with airbag deployment when seatbelts are not used are concerning. After activation of the airbag sensor by the deceleration produced by an impact, airbag deployment velocity ranges from 158 to $340 \mathrm{~km} /$ hour (98 to $211 \mathrm{miles} /$ hour), which causes sudden deceleration of the thoracic cage and potentially spinal column and neurological injury in front-row occupants. ${ }^{24}$ Given that airbags are almost universal in modern vehicles, our findings merit public education on this additional risk to front-seat occupants without seatbelts.

The PDOF in an MVC has been associated with the severity of the injuries that result. ${ }^{36,38,40}$ Compared with frontal collisions, lateral-impact MVCs have been associated with an increase in the odds of death (OR 12.86) and a higher incidence of severe brain and pelvic injuries..$^{34,36}$ In our study, we found that lateral-impact collisions did not differ from frontal collisions with respect to either the risk or the severity of neurological injury. The increased protection in lateral-impact MVCs found in this study may be related to the increased deployment of side airbags in more recently manufactured motor vehicles. Side-airbag deployment has been reported to reduce the risk of injuries to the thorax by $68 \%$ in lateral-impact collisions. ${ }^{23}$ Failure of side-airbag deployment, reported in as high as 34\% of severe side-impact collisions, may leave the occupant unprotected in the event of a lateral impact. ${ }^{41}$ Side-airbag deployment also has been seen to fail when the initial point contact is frontal but with a significant lateral PDOF component. ${ }^{41}$ We are in agreement with the recommendation made by Stadter et al. ${ }^{41}$ to place another set of side-impact airbag sensors in the front of the vehicle to reduce the risk of thoracolumbar spinal neurological injury in lateral-impact collisions.

Many previous authors have identified vehicle rollover as a risk factor for SCI in occupants of MVCs. ${ }^{3,28,44}$ Stein et al. ${ }^{42}$ performed a univariate analysis of 2 separate databases of MVCs and found strong associations between both cervical spinal column injury and SCI with vehicle rollover. Conversely, we found the incidence of thoracolumbar SCI to be similar in collisions that involved vehicle rollover compared with that in non-rollover collisions. We assume that this discrepancy in susceptibility to SCI from rollover collisions results from the superior protection of the thoracolumbar spine by the rib cage, and the more protected position of the thoracolumbar spine in the seat against injury, as opposed to the cervical spinal column.

Our study has several strengths. Data on the occupants enrolled in this study were from a large and detailed multicenter database, which constitutes the largest series of thoracolumbar fractures with resulting neurological deficit caused by MVCs. We believe that this database increased the diversity of case occupants in our study, is representative of the general population, and increases the validity of our findings. Patients with typical "whiplash" are excluded from the CIREN database, which represents more severely injured patients, and the findings can reasonably and fairly be extrapolated to patients admitted to Level I trauma centers nationwide. The study does, however, have some limitations. The CIREN database was queried for data between 1996 and 2011. Because our study was retrospective in design, improvements in vehicle safety features and improved collision tolerances over this period, such as improvement in the crush profiles of vehicles, improvement in roof design, and improvements in airbag sensors, were not incorporated in the assessment of risk for injury. In addition, the AIS scoring system was revised between 1996 and 2011, potentially resulting in differences in the AIS and ISS scores documented for similar injuries in the CIREN database. Given the multicenter nature of the CIREN database and the large number of subjects, missing data are inherent, and we found missing information on use of seatbelts, airbag deployment, and $\Delta \mathrm{V}$ for a number of subjects. Other limitations of our study are the de- 
signed inclusion of occupants who sustained serious injury or died and the study's retrospective nature, which introduce the possibility of recall bias, particularly in fatal cases in which SCI was diagnosed by either autopsy records or documentation from medical records in the emergency department or on admission to the trauma center. Our results and conclusions are based on a univariate analysis that may not be reflective of all factors that predispose occupants to injury. Finally, the number of subjects who sustained lumbosacral nerve root and conus medullaris injury was small, and subtle details of neurological presentations were not available; thus, the results of the analysis of these specific injuries carry lower validity.

\section{Conclusions}

The results of our study clearly demonstrate the protective role of airbags that deploy in conjunction with the use of 3-point seatbelts in preventing and reducing the severity of neurological injury associated with thoracolumbar spine fractures in MVC occupants. When deployed alone without concurrent seatbelt use, airbags do not protect against thoracolumbar neurological injury. In addition to airbag and seatbelt restraint, the incidence of neurological injury at the thoracic and lumbar levels is affected by multiple factors in an MVC, including the incidence of fatality, occupant factors, energy at impact, and direction of impact. Current vehicular safety engineering needs to be reevaluated for individuals with various body morphologies and torso compliance to specifically address the overall risk of injury to the thoracolumbar spinal cord and the lumbosacral nerve roots.

\section{Acknowledgments}

This research was supported in part by US DOT NHTSA CIREN research funds DTNH22-10-H-00292 and by the Department of Veterans Affairs Medical Research. The views expressed are those of the authors and do not represent those of the funding agency.

\section{References}

1. Anderton BH: Changes in the ageing brain in health and disease. Philos Trans R Soc Lond B Biol Sci 352:1781-1792, 1997

2. Bose D, Segui-Gomez M, Crandall JR: Vulnerability of female drivers involved in motor vehicle crashes: An analysis of US population at risk. Am J Public Health:2368-2373, 2011

3. Cushman LA, Good RG, States JD: Characteristics of motor vehicle accidents resulting in spinal cord injury. Accid Anal Prev 23:557-560, 1991

4. DeVivo MJ, Chen Y: Trends in new injuries, prevalent cases, and aging with spinal cord injury. Arch Phys Med Rehabil 92:332-338, 2011

5. Dischinger PC, Siegel JH, Ho SM, Kufera JA: Effect of change in velocity on the development of medical complications in patients with multisystem trauma sustained in vehicular crashes. Accid Anal Prev 30:831-837, 1998

6. Evans L: Fatality risk reduction from safety belt use. J Trauma 27:746-749, 1987

7. Gabauer DJ, Gabler HC: Comparison of delta-v and occupant impact velocity crash severity metrics using event data recorders. Annu Proc Assoc Adv Automot Med 50:57-71, 2006
8. Gennarelli TA, Wodzin E: AIS 2005: a contemporary injury scale. Injury 37:1083-1091, 2006

9. Harré N, Field J, Kirkwood B: Gender differences and areas of common concern in the driving behaviors and attitudes of adolescents. J Safety Res 27:163-173, 1996

10. Hart RA, Mayberry JC, Herzberg AM: Acute cervical spinal cord injury secondary to air bag deployment without proper use of lap or shoulder harnesses. J Spinal Disord 13:36-38, 2000

11. Jonah BA: Age differences in risky driving. Health Educ Res 5:139-149, 1990

12. Kaplan BH, Cowley RA: Seatbelt effectiveness and cost of noncompliance among drivers admitted to a trauma center. Am J Emerg Med 9:4-10, 1991

13. Kent R, Lee SH, Darvish K, Wang S, Poster CS, Lange AW, et al: Structural and material changes in the aging thorax and their role in crash protection for older occupants. Stapp Car Crash J 49:231-249, 2005

14. Kent R, Woods W, Bostrom O: Fatality risk and the presence of rib fractures. Ann Adv Automot Med 52:73-82, 2008

15. Kirshblum SC, Waring W, Biering-Sorensen F, Burns SP, Johansen M, Schmidt-Read M, et al: Reference for the 2011 revision of the international standards for neurological classification of spinal cord injury. J Spinal Cord Med 34:547554,2011

16. Lin H, Schlaepfer WW: Role of neurofilament aggregation in motor neuron disease. Ann Neurol 60:399-406, 2006

17. Lindner AB, Demarez A: Protein aggregation as a paradigm of aging. Biochim Biophys Acta 1790:980-996, 2009

18. Linn S: The injury severity score-importance and uses. Ann Epidemiol 5:440-446, 1995

19. Liu C, Utter D, Chen CL: Characteristics of Crash Injuries Among Young, Middle-Aged, and Older Drivers. DOT HS 810 857. Washington, DC: National Highway Traffic Safety Administration, 2007

20. Marcus JH, Morgan RM, Eppinger RH, Kallieris D, Mattern R, Schmidt G: Human response to and injury from lateral impact. Stapp Car Crash J 27:419-432, 1983

21. Marino RJ, Ditunno JF Jr, Donovan WH, Maynard F Jr: Neurologic recovery after traumatic spinal cord injury: data from the Model Spinal Cord Injury Systems. Arch Phys Med Rehabil 80:1391-1396, 1999

22. Maynard FM Jr, Bracken MB, Creasey G, Ditunno JF Jr, Donovan WH, Ducker TB, et al: International standards for neurological and functional classification of spinal cord injury. Spinal Cord 35:266-274, 1997

23. McGwin G Jr, Metzger J, Alonso JE, Rue LW III: The association between occupant restraint systems and risk of injury in frontal motor vehicle collisions. J Trauma 54:1182-1187, 2003

24. Morrison AL, Chute D, Radentz S, Golle M, Troncoso JC, Smialek JE: Air bag-associated injury to a child in the front passenger seat. Am J Forensic Med Pathol 19:218-222, 1998

25. Murphy RX Jr, Birmingham KL, Okunski WJ, Wasser T: The influence of airbag and restraining devices on the patterns of facial trauma in motor vehicle collisions. Plast Reconstr Surg 105:516-520, 2000

26. National Highway Traffic Safety Administration: Traffic Safety Facts 2012. Washington, DC: US Department of Transportation, 2012

27. National Spinal Cord Injury Statistical Center: 2013 Annual Statistical Report for the Spinal Cord Injury Model Systems. Birmingham, AL: University of Alabama at Birmingham, 2013

28. O'Connor P: Incidence and patterns of spinal cord injury in Australia. Accid Anal Prev 34:405-415, 2002

29. O'Connor P: Injury to the spinal cord in motor vehicle traffic crashes. Accid Anal Prev 34:477-485, 2002 
30. O'Connor PJ, Brown D: Relative risk of spinal cord injury in road crashes involving seriously injured occupants of light passenger vehicles. Accid Anal Prev 38:1081-1086, 2006

31. Price C, Makintubee S, Herndon W, Istre GR: Epidemiology of traumatic spinal cord injury and acute hospitalization and rehabilitation charges for spinal cord injuries in Oklahoma, 1988-1990. Am J Epidemiol 139:37-47, 1994

32. Rao RD, Berry CA, Yoganandan N, Agarwal A: Occupant and crash characteristics in thoracic and lumbar spine injuries resulting from motor vehicle collisions. Spine J 14:2355-2365, 2014

33. Reed MA, Naftel RP, Carter S, MacLennan PA, McGwin G Jr, Rue LW III: Motor vehicle restraint system use and risk of spine injury. Traffic Inj Prev 7:256-263, 2006

34. Ryb GE, Dischinger PC, Kufera JA, Burch CA: Delta V, principal direction of force, and restraint use contributions to motor vehicle crash mortality. J Trauma 63:1000-1005, 2007

35. Schmidt G, Kallieris D, Barz J, Mattern R, Klaiber J: Neck and thorax tolerance levels of belt-protected occupants in head-on collisions. Stapp Car Crash J 19:225-258, 1975

36. Siegel JH, Loo G, Dischinger PC, Burgess AR, Wang SC, Schneider LW, et al: Factors influencing the patterns of injuries and outcomes in car versus car crashes compared to sport utility, van, or pick-up truck versus car crashes: Crash Injury Research Engineering Network Study. J Trauma 51:975-990, 2001

37. Siegel JH, Mason-Gonzalez S, Dischinger P, Cushing B, Read K, Robinson R, et al: Safety belt restraints and compartment intrusions in frontal and lateral motor vehicle crashes: mechanisms of injuries, complications, and acute care costs. J Trauma 34:736-759, 1993

38. Siegel JH, Smith JA, Siddiqi SQ: Change in velocity and energy dissipation on impact in motor vehicle crashes as a function of the direction of crash: key factors in the production of thoracic aortic injuries, their pattern of associated injuries and patient survival. A Crash Injury Research Engineering Network (CIREN) study. J Trauma 57:760-778, 2004

39. Smith DP, Klein FA: Renal injury in a child with airbag deployment. J Trauma 42:341-342, 1997

40. Smith JA, Siegel JH, Siddiqi SQ: Spine and spinal cord injury in motor vehicle crashes: a function of change in velocity and energy dissipation on impact with respect to the direction of crash. J Trauma 59:117-131, 2005

41. Stadter G, Grabowski JG, Burke C, Aldaghlas TA, Robinson L, Fakhry SM: Injury and side impact air bag deployment in near and far sided motor vehicle crashes, United States, 2000-2005. J Trauma 65:1333-1339, 2008
42. Stein DM, Kufera JA, Ho SM, Ryb GE, Dischinger PC, O'Connor JV, et al: Occupant and crash characteristics for case occupants with cervical spine injuries sustained in motor vehicle collisions. J Trauma 70:299-309, 2011

43. Stoneham MD: Bilateral first rib fractures associated with driver's air bag inflation: case report and implications for surgery. Eur J Emerg Med 2:60-62, 1995

44. Thurman DJ, Burnett CL, Beaudoin DE, Jeppson L, Sniezek JE: Risk factors and mechanisms of occurrence in motor vehicle-related spinal cord injuries: Utah. Accid Anal Prev 27:411-415, 1995

45. US Department of Transportation: NHTSA Data Reference Guide Version 4. Washington, DC: National Highway Traffic Safety Administration, 1997

46. Wang MC, Pintar F, Yoganandan N, Maiman DJ: The continued burden of spine fractures after motor vehicle crashes. J Neurosurg Spine 10:86-92, 2009

47. Wigglesworth EC: Motor vehicle crashes and spinal injury. Paraplegia 30:543-549, 1992

48. Yip PK, Malaspina A: Spinal cord trauma and the molecular point of no return. Mol Neurodegener 7:6, 2012

49. Zhou Q, Rouhana SW, Melvin JW: Age effects on thoracic injury tolerance. Stapp Car Crash J 40:137-148, 1996

\section{Disclosure}

The authors report no conflict of interest concerning the materials or methods used in this study or the findings specified in this paper.

\section{Author Contributions}

Conception and design: Rao, Yoganandan. Acquisition of data: Rao, Mukherjee, Yoganandan. Analysis and interpretation of data: all authors. Drafting the article: all authors. Critically revising the article: all authors. Reviewed submitted version of manuscript: all authors. Approved the final version of the manuscript on behalf of all authors: Rao. Statistical analysis: Mukherjee, Yoganandan. Administrative/technical/material support: Rao, Yoganandan. Study supervision: Rao, Yoganandan.

\section{Correspondence}

Raj D. Rao, Department of Orthopaedic Surgery, George Washington University, 2300 M Street, NW, 5th Floor, Washington, DC 20037. 